throughout this period of inquiry and have co-operated to the fullest extent with the unit.

To obtain information concerning the incidence of ectopic pregnancy it is necessary to use studies which have a very large IUD data base. The pregnancy rate among IUD users is rarely above 4.0 per 100 users per year and the ectopic pregnancy rate has been estimated as being between 1 in 20 and 1 in 30 of these pregnancies. This unit has a very large data base relating to approximately 45000 IUD fittings describing the IUDs commonly available in the UK. The Progestasert is a relatively new device and only one large-scale study has been reported. ${ }^{1}$ Another independent study of the Progestasert is currently under way under the auspices of WHO, but this study is relatively small in size. No other large-scale studies of the Progestasert have been reported in Britain or elsewhere.

On examining more carefully the data presented in the Alza report ${ }^{1}$ I discovered that the incidence of extrauterine pregnancy among women using the Progestasert was reported as being $21 \%$ of all pregnancies. This crude figure of 1 in 5 pregnancies appeared to be much higher than that reported for other IUDs in other studies. The Alza report was made available to the American Food and Drug Administration (FDA) and the UK Committee on the Safety of Medicines, and neither organisation appeared to query this statistic. This finding could easily be missed on a first reading of the report (as I did myself), perhaps owing to the way in which the data have been presented in the report. There is a mixture of the three ways of presenting such information: the proportion of pregnancies reported, the rate per 100 women, and the more involved expected $v$ achieved rate per 1000 conceptions.

On realising the importance of this finding I analysed the data relating to all IUD pregnancies held at the unit according to these three systems of analysis. The results are contained in the accompanying table. Notice that "inert" and "copper" devices to the first 12 months of use, as this gives a fairer comparison with the Progestasert, which is routinely removed at the end of 12 months.

Among the population selected in the Alza study a rate of 0.4 ectopic pregnancies per 100 woman-years of observation was discovered-I compared this rate among other women wearing other (non-progesteronereleasing) devices and found the rate to be about 0.06 per 100 woman-years. This shows a difference in magnitude of between 6 and 7 times when comparing the Progestasert with other devices. The question is then asked, I have restricted the pregnancies for the

can we really compare these two sets of data? My contention is that while we cannot be certain of a causal relationship between use of the Progestasert and an increased incidence of ectopic pregnancy on this type of evidence, we can say that a case has been made for further detailed investigation. It is pending the results of this investigation that the distributors have voluntarily ceased to recommend its use. If it can be shown that the population selected from the Alza study has an unusually high incidence of ectopic pregnancy compared with the UK population, then this will partly explain the difference in rates between the devices described in the table. But the differences are very large and suggest the need for a full and careful investigation.

The unit is not in a position to provide evidence which confirms the cause of ectopic pregnancy among IUD users, but we can say that women who become pregnant when wearing an IUD are more likely to have an ectopic pregnancy than those not wearing an IUD. For the first time we have evidence that the type of IUD may be relating to an increased incidence.

It should be emphasised that the company responsible for distributing the device in the $\mathrm{UK}$ was as unaware of this problem as those who first read the report describing the original trial. It is only as the result of subsequent detailed examination of the data that the increased ectopic pregnancy rate has come to light. I understand that the submission to the licensing authority in the UK was based on the data produced by Alza for the FDA and a product licence was granted before the UK distributor was appointed.

In order to obtain some evidence concerning the possible incidence of ectopic pregnancy among Progestasert users in the UK I would be very pleased to receive any relevant information from those who have fitted this device since its introduction in January 1977.

\section{ROBERT SNOWDEN} Project Director,
Family Planning Research Unit

Department of Sociology, 'Alza Corporation, The Progestasert-Progesterone
Uterine Therapeutic System. AProduct Profile, 1976.

\section{Renovating acute wards in older} hospitals

SIR,-The recent special allocation of $£ 55 \mathrm{~m}$ over 18 months to the NHS towards the urgent task of renovation and maintenance ${ }^{1}$ was most welcome news. Mr David Ennals intends to help particularly the long-stay

Ectopic pregnancies

\begin{tabular}{|c|c|c|c|}
\hline & $\begin{array}{c}\text { Based on } \\
\text { conception rate } \\
\text { (Tietze method) }\end{array}$ & $\begin{array}{l}\text { Per } 100 \text { women } \\
\text { (Pearl Index) }\end{array}$ & $\begin{array}{c}\text { Ectopic } \\
\text { pregnancies as a } \\
\text { proportion of } \\
\text { pregnancies } \\
\text { occurring }\end{array}$ \\
\hline All Lippes Loop IUDs ( 4 sizes $(n=6872)$ & $\begin{array}{l}\text { Expected } 34-51 \\
\text { Observed } 3 \\
\text { Reduction of } 91-94^{\circ}\end{array}$ & 0.06 & $\begin{array}{l}4 \cdot 2^{\circ}{ }^{\prime \prime} \\
(1: 24)\end{array}$ \\
\hline $\begin{array}{l}\text { Copper-carrying IUDs }(\mathrm{Cu}-7 \text { and } \mathrm{Cu}-\mathrm{T}) \\
(\mathrm{n}=9596)\end{array}$ & $\begin{array}{l}\text { Expected } 45-68 \\
\text { Observed } 2 \\
\text { Reduction of } 96-97^{\prime \prime},\end{array}$ & 0.05 & $\begin{array}{l}1 \cdot 7^{\prime \prime} \\
(1: 57)\end{array}$ \\
\hline $\begin{array}{l}\text { Progesterone-releasing IUD (Progestasert) } \\
(\mathrm{n}=6813)\end{array}$ & $\begin{array}{l}\text { Expected } 39-58 \\
\text { Observed } 17 \\
\text { Reduction of } 56-71^{\circ}\end{array}$ & $0 \cdot 37$ & $\begin{array}{l}21 \% \\
(1: 5)\end{array}$ \\
\hline
\end{tabular}

All the rates given above are based on the first year of use only.
Source of data for all devices other than the Progestasert-Family Planning Research Unit, IUD data bank. The Progestasert data are extracted from the Alza report. patients in geriatric and mental care units. May I make a plea for some of this money to go towards upgrading acute wards in our main district general hospitals, many of which have suffered from planning blight ever since the hospital rebuilding plan began in 1960 ?

Many of these hospitals, built $75-100$ years ago, are likely to remain in service for a long time yet, and particularly in large conurbations to remain the backbone of the hospital service. The new hospitals which have been built are proving expensive to run and now drain the resources of their neighbours. Fortunately the solidly built older hospitals can be refitted relatively inexpensively. The muchneeded toilets and extra rooms can be added without loss of the homely, friendly atmosphere which tends to be missing from our newer hospitals. Most short-stay patients in acute wards tolerate the inadequate conditions, appreciating the excellence of the nursing and medical care, but a few may strongly object. It is the ward staff who are being constantly frustrated and irritated by trying to privde present-day medicine under substandard conditions.

I believe the time has come to abandon the pretence that every district hospital in the country is going to be rebuilt in measurable time. It would be a wonderful help to morale if the Secretary of State sponsored a plan to provide reasonable basic conditions for the principal older district general hospitals which carry such a heavy load of acute work. For the next decade refitting should have priority over building new "nucleus" hospitals. A "doomsday"-type survey, as was done for schools, would quickly assess the magnitude and regional variations of the problem. Of course it must run pari passu with the upgrading of long-stay units. An imaginative plan might achieve considerable financial support both from the public and from charitable foundations.

London W1

F AVERY JONES Hansard, House of Commons, 4 November 1977,

\section{Structure of vocational training programmes}

SIR,-I would like to thank you for publishing Dr Conrad Harris's stimulating Personal View (12 November, $p$ 1282). His vision of a change in the way in which a three-year vocational training programme is balanced between hospital and general practice is, I am sure, shared by many of those who actually run such programmes. The stumbling block is the Department of Health and Social Security, which has repeatedly refused to fund more than 12 months as a trainee general practitioner. If this hurdle could be overcome, then schemes up and down the country could experiment with release from general practice to hospital in order to increase the trainees' knowledge and skills in clinical medicine. However, I suspect that even without any stumbling block there would always need to be some period of experience in a hospital residency at senior house officer level. This is because the expected benefits from a post in general medicine are unlikely to be achieved by sessional release from general practice.

I should like to differ from Dr Harris on just one point that he makes in his article. This is in relation to the half-day release programme that is an integral part of any vocational train- 